\title{
НА ПУТИ ПОИСКА НАУЧНЫХ ПРИНЦИПОВ ЭКОНОМИЧЕСКОЙ ПЕРИОДИЗАЦИИ ЧЕЛОВЕЧЕСКОГО ОБЩЕСТВА
}

\author{
(C) 2020 Гуськова Марина Федоровна \\ доктор экономических наук, профессор, профессор кафедры «Менеджмент качества» \\ Российский университет транспорта (МИИТ), Россия, Москва \\ (c) 2020 Стерликов Павел Федорович \\ доктор экономических наук, профессор, зав. кафедрой «Экономическая теория» \\ МГМСУ им. А.И. Евдокимова Минздрава России, Россия, Москва \\ (c) 2020 Стерликов Федор Федорович \\ доктор экономических наук, профессор, \\ лауреат премии Правительства Российской Федерации в области науки и техники \\ МГУТУ(ПКУ) им. К.Г. Разумовского, Россия, Москва
}

Анализируются основные концепции экономической периодизации истории человеческого общества и возможности их использования для характеристики современного состояния экономики. Уточнен метод анализа экономической периодизации и его применение.

Ключевые слова: периодизация экономической истории, основные концепции периодизации, революционная и эволюционная концепции, диалектика экономических отношений.

\section{Вместо введения}

Нами ставилась задача - в результате исследования выявить и теоретически доказать наличие определенных закономерностей развития экономических отношений человеческого общества, найти аргументы и факты их существования, показать формы проявления этих закономерностей, служащих исходными пунктами и опорой для характеристики современного состояния мировой и отечественной экономики.

Экономическая периодизация человеческого общества на различных этапах исторического развития, отличающаяся уровнем развития экономики, способом производства материальных благ, развитием производительных сил, совокупностью производственных отношений, анализируется с использованием различных методологических подходов.

Наиболее известными являются следующие подходы:

- формационный, базирующийся на учете различий базиса и надстройки, обуславливающий следующие периоды - первобытнообщинный, рабовладельческий, феодальный, капиталистический, коммунистический;

- индустриальный, базирующийся на учете различий в средствах производства, обуславливающий следующие периоды - до индустриальный, индустриальный, послеиндустриальный;
- экономический уклад, базирующийся на учете различий в предметах труда - первый экономический уклад, второй экономический уклад, третий экономический уклад, четвертый экономический уклад.

Для анализа единства исторического и логического историко-экономического аспекта избран логический (структурный) подход, фиксирующий внимание не только на фактологической стороне исторического развития, но в большей мере на логичности этого развития. При этом использовался и прагматический подход, обусловливающий не только поиск закономерностей развития экономических отношений человеческого общества, но и извлечение из этих результатов определенных практических выгод для пользователей теории.

\section{О методе исследования}

Организм социальный - англ. organism, social; нем. Organismus, sozialer. Совокупность различных сторон жизнедеятельности данного общества, взаимодействие которых придает ему целостный характер [Энциклопедия социологии, 2009].

Экономисты А. Смит и Д. Юм определили общество как трудовой союз людей, связанных разделением труда, а философ И. Кант - как человечество, взятое в историческом развитии.

Каждый уровень развития общества пред- 
ставляет собой особый социальный организм, отличающийся от других не менее глубоко, чем отличаются друг от друга различные биологические виды. В послесловии ко 2-му изданию «Капитала» К. Маркс приводил высказывание русского рецензента книги, по мнению которого её истинная цена заключается в «...выяснении тех частных законов, которым подчиняются возникновение, существование, развитие, смерть данного социального организма и заменение его другим, высшим».

«Иному читателю может при этом прийти на мысль и такой вопрос... ведь общие законы экономической жизни одни и те же, все равно, применяются ли они к современной или прошлой жизни? Но именно этого Маркс не признает. Таких общих законов для него не существует... По его мнению, напротив, каждый крупный исторический период имеет свои законы... Но как только жизнь пережила данный период развития, вышла из данной стадии и вступила в другую, она начинает управляться уже другими законами. Словом, экономическая жизнь представляет нам в этом случае явление, совершенно аналогичное тому, что мы наблюдаем в других разрядах биологических явлений... Старые экономисты не понимали природы экономических законов, считая их однородными с законами физики и химии... Более глубокий анализ явлений показал, Что социальные организмы отличаются друг от друга не менее глубоко, чем организмы ботанические и зоологические... Одно и то же явление, вследствие различия в строе этих организмов, разнородности их органов, различий условий, среди которых органам приходится функционировать, и т.д., подчиняется совершенно различным законам [Там же].

«Санкт-Петербургские ведомости» в номере от 8 (20) апреля 1872 г. между прочим замечают: «Изложение его труда (исключая некоторые слишком специальные частности) отличается ясностью, общедоступностью и, несмотря на научную высоту предмета, необыкновенной живостью. В этом отношении автор... далеко не походит на большинство немецких ученых, которые... пишут свои сочинения таким темным и сухим языком, от которого у обыкновенных смертных трещит голова». У читателей современной немецко-национально-либеральной профессорской литературы трещит не голова, а кое-что совершенно другое.

Раз он открыл этот закон, он рассматривает подробнее последствия, в которых закон проявляется в общественной жизни... Сообразно с этим Маркс заботится только об одном: чтобы точным научным исследованием доказать необходимость определенных порядков общественных отношений и чтобы возможно безупречнее констатировать факты, служащие ему исходными пунктами и опорой. Для него совершенно достаточно, если он, доказав необходимость современного порядка, доказал и необходимость другого порядка, к которому непременно должен быть сделан переход от первого, все равно, думают ли об этом или не думают, сознают ли это или не сознают. Маркс рассматривает общественное движение как естественноисторический процесс, которым управляют законы, не только не находящиеся в зависимости от воли, сознания и намерения человека, но и сами еще определяющие его волю, сознание и намерения... Если сознательный элемент в истории культуры играет такую подчиненную роль, то понятно, что критика, имеющая своим предметом самую культуру, всего менее может иметь своим основанием какую-нибудь форму или какой-либо результат сознания. То есть не идея, а внешнее явление одно только может ей служить исходным пунктом. Критика будет заключаться в сравнении, сопоставлении и сличении факта не с идеей, а с другим фактом. Для нее важно только, чтобы оба факта были возможно точнее исследованы и действительно представляли собой различные степени развития, да сверх того важно, чтобы не менее точно были исследованы порядок, последовательность и связь, в которых проявляются эти степени развития... Иному читателю может при этом прийти на мысль и такой вопрос... ведь общие законы экономической жизни одни и те же, все равно, применяются ли они к современной или прошлой жизни? Но именно этого Маркс не признает. Таких общих законов для него не существует... По его мнению, напротив, каждый крупный исторический период имеет свои законы... Но как только жизнь пережила данный период развития, вышла из данной стадии и вступила в другую, она начинает управляться уже другими законами. Словом, экономическая жизнь представляет нам в этом случае явление, совершенно аналогичное тому, что мы наблюдаем в других разрядах биологических явлений... Старые экономисты не понимали природы экономических законов, считая их однородными с законами физики и химии... 
Более глубокий анализ явлений показал, Что социальные организмы отличаются друг от друга не менее глубоко, чем организмы ботанические и зоологические... Одно и то же явление, вследствие различия в строе этих организмов, разнородности их органов, различий условий, среди которых органам приходится функционировать, и т.д., подчиняется совершенно различным законам. Маркс отказывается, например, признавать, что закон увеличения народонаселения один и тот же всегда и повсюду, для всех времен и для всех мест. Он утверждает, напротив, что каждая степень развития имеет свой закон размножения... В зависимости от различий в уровне развития производительных сил изменяются отношения и законы, их регулирующие. Задаваясь, таким образом, целью - исследовать и объяснить капиталистический порядок хозяйства, Маркс только строго научно формулировал цель, которую может иметь точное исследование экономической жизни... Его научная цена заключается в выяснении тех частных законов, которым подчиняются возникновение, существование, развитие, смерть данного социального организма и заменение его другим, высшим. И эту цену действительно имеет книга Маркса».

Автор, описав так удачно то, что он называет моим действительным методом, и отнесшись так благосклонно к моим личным приемам применения этого метода, тем самым описал не что иное, как диалектический метод.

Конечно, способ изложения не может с формальной стороны не отличаться от способа исследования. Исследование должно детально освоиться с материалом, проанализировать различные формы его развития, проследить их внутреннюю связь. Лишь после того как эта работа закончена, может быть надлежащим образом изображено действительное движение. Раз это удалось и жизнь материала получила свое идеальное отражение, то может показаться, что перед нами априорная конструкция.

Мой диалектический метод по своей основе не только отличен от гегелевского, но является его прямой противоположностью. Для Гегеля процесс мышления, который он превращает даже под именем идеи в самостоятельный субъект, есть демиург действительного, которое составляет лишь его внешнее проявление. У меня же, наоборот, идеальное есть не что иное, как материальное, пересаженное в человеческую голову и преобразованное в ней.
Мистифицирующую сторону гегелевской диалектики я подверг критике почти 30 лет тому назад, в то время, когда она была еще в моде. Но как раз в то время, когда я работал над первым томом «Капитала», крикливые, претенциозные и весьма посредственные эпигоны, задающие тон в современной образованной Германии, усвоили манеру третировать Гегеля, как некогда, во времена Лессинга, бравый Мозес Мендельсон третировал Спинозу, как «мертвую собаку». Я поэтому открыто объявил себя учеником этого великого мыслителя и в главе о теории стоимости местами даже кокетничал характерной для Гегеля манерой выражения. Мистификация, которую претерпела диалектика в руках Гегеля, отнюдь не помешала тому, что именно Гегель первый дал всеобъемлющее и сознательное изображение ее всеобщих форм движения. У Гегеля диалектика стоит на голове. Надо ее поставить на ноги, чтобы вскрыть под мистической оболочкой рациональное зерно.

В своей мистифицированной форме диалектика стала немецкой модой, так как казалось, будто она прославляет существующее положение вещей. В своем рациональном виде диалектика внушает буржуазии и ее доктринерамидеологам лишь злобу и ужас, так как в позитивное понимание существующего она включает в то же время понимание его отрицания, его необходимой гибели, каждую осуществленную форму она рассматривает в движении, следовательно также и с ее преходящей стороны, она ни перед чем не преклоняется и по самому существу своему критична и революционна.

Полное противоречий движение капиталистического общества всего осязательнее дает себя почувствовать буржуа-практику в колебаниях проделываемого современной промышленностью периодического цикла, апогеем которых является общий кризис. Кризис опять надвигается, хотя находится еще в своей начальной стадии, и благодаря разносторонности и интенсивности своего действия он вдолбит диалектику даже в головы выскочек новой священной прусско-германской империи.

\section{Формационый подход.}

Формация - это общество на определенном этапе исторического развития, основным критерием которого является развитие экономики, способ производства материальных благ, уровень развития производительных сил, совокуп- 
ность производственных отношений.

Главная задача экономики как области практической деятельности - произвести больше благ из ограниченных ресурсов. Главная задача экономики как области теоретической деятельности - поиск путей максимизации удовлетворения потребностей ограниченными ресурсами.

Критерием эффективности использования ограниченных ресурсов для удовлетворения безграничных потребностей является экономический рост. Показателем этого критерия выступает производительность труда. Производительность определяется количеством товаров и услуг (благ), изготовленных за год в стране, либо в абсолютной величине, либо в расчете на одного жителя страны. Производительность труда может: 1) расти; 2) не изменяться; 3) уменьшаться. Человеческое общество и каждого человека лично устраивает только рост производительности труда! Главная задача экономики решается наилучшим образом, конечно же, при росте производительности труда: больше производится товаров и услуг больше удовлетворяется потребностей. По состоянию производительности труда можно судить об экономическом прогрессе:

- при росте производительности в экономике прогресс;

- при неизменной производительности застой;

- при снижении кризис или регресс.

На любом историческом этапе человечество в целом или отдельные страны в частности решают главную задачу экономики путем преодоления главного экономического противоречия - противоречия между безграничными потребностями и ограниченными ресурсами. Главная задача экономики решается путем обеспечения роста производительности труда, роста производства товаров и услуг в расчете на каждого жителя страны. Каждое общество обеспечивает экономический прогресс, решает главную задачу экономики своими специфическими путями. Результатом прогрессивного экономического развития является рост благосостояния людей, рост степени удовлетворения их потребностей.

Есть несколько подходов и концепций, объясняющих экономический прогресс (формационный, цивилизационный и др.). Наиболее разработанным является формационный подход.

Формационный подход лежит в основе революционной концепции экономического

прогресса (как части общественного прогресса).

Рассмотрим общую логику экономического прогресса в этой концепции и попытаемся подвергнуть ее критическому анализу.

Представляемая концепция базируется на признании пяти последовательно сменяемых друг друга формаций и как их составной части пяти способов хозяйствования:

- первобытнообщинного;

- рабовладельческого;

- феодального;

- капиталистического;

- коммунистического. Поскольку последний способ хозяйствования на практике в развитом состоянии неизвестен, для анализа принимается во внимание только теорию.

Способ хозяйствования в соответствии с рассматриваемой концепцией включает следующие составные части:

- производительные силы (предметы труда, средства труда и рабочая сила);

- производственные отношения (отношения людей в процессе производства).

Предполагается (и не без основания), что производительные силы развиваются непрерывно: улучшаются средства труда, совершенствуется опыт и навыки производителей, в итоге больше производится благ (товаров и услуг), лучше удовлетворяются потребности, а значит, непрерывно растет производительность труда. Значение производственных отношений (отношений людей в процессе производства) в данной концепции соответствовать уровню развития производительных сил. Более того, признается наличие закона соответствия производственных отношений уровню и характеру производительных сил. Соответствие производственных отношений и производительных сил означает, что производственные отношения способствуют развитию производительных сил, росту производительности труда. Несоответствие же означает, что производственные отношения тормозят развитие производительных сил. Либо рост производительности труда останавливается, либо производительность труда снижается.

Рассматриваемая концепция следующим образом объясняет переход от одной хозяйственной системы к другой с целью обеспечения экономического прогресса.

В начале каждой хозяйственной системы 
производственные отношения соответствуют производительным силам, обеспечивают рост производительности труда. По истечении определенного времени появляются противоречия между производительными силами и производственными отношениями появляются такие элементы производственных отношений, которые тормозят рост производительности труда. Далее противоречия обостряются: количество противоречий и их острота возрастают. Наконец, противоречия достигают антагонизма нетерпимости. Антагонистические противоречия разрешаются только одним путем - путем уничтожения одной из сторон противоречия. В рассматриваемом случае производственные отношения данного способа хозяйствования уничтожаются “до основания, а затем” появляются новые производственные отношения. Таким образом, переход от одной хозяйственной системы к другой, переход от одних производственных отношений к другим обеспечивает непрерывный рост производительности общественного труда. Таково содержание революционной концепции экономического прогресса.

После изложения сути революционной концепции экономического прогресса возникает вопрос: Обязательно ли противоречия между производительными силами и производственными отношениями должны достигать антагонизма (нетерпимости)?

Поставленный выше вопрос с точки зрения рассматриваемой концепции содержит крамолу - ведь усомниться в необходимости революционной замены старых производственных отношений новыми производственными отношениями значит усомниться в необходимости экономического прогресса. Можно согласиться с теми, кто считает, что противоречия должны достигать антагонизма. Ведь, согласно рассматриваемой концепции, без антагонизма и последующего уничтожения старых производственных отношений и их замены новыми производственными отношениями не обеспечить непрерывность роста производительности труда, экономического прогресса. Таким образом, антагонизм и последующая революционная замена старых производственных отношений новыми производственными отношениями, согласно рассмотренной концепции необходимое условие экономического прогресса.

Однако можно усомниться в истинности рассмотренной концепции и выдвинуть собствен- ную гипотезу.

Гипотеза: «Производственные отношения любого способа хозяйствования состоят из двух групп отношений:

- первая группа состоит из элементов, оставшихся от прежних способов хозяйствования,

- вторая группа - это производственные отношения нового способа хозяйствования».

Выдвинутая гипотеза противоречит рассмотренной выше концепции экономического прогресса. В самом деле, если что-то осталось от предыдущих производственных отношений, то это значит, что они не уничтожены до основания, а значит, и противоречия между производительными силами и производственными отношениями не достигали антагонизма.

Для проверки правильности выдвинутой гипотезы необходимо провести анализ производственных отношений в исторической последовательности и попытаться найти те элементы производственных отношений, которые сохранялись и переходили в последующие хозяйственные системы. Если это удастся, то гипотеза окажется доказанной и превратится в новую теорию (концепцию) экономического прогресса.

1. Экономический прогресс при первобытнообщинном способе хозяйствования. Рассмотрим хозяйствование на начальном этапе первобытной общины. На этом этапе удовлетворялись самые первичные, физиологические потребности в пище, одежде, жилище. Блага добывались в основном путем собирательства плодов и ягод и охоты (мясо на еду, шкура на одежду и строительство жилища). Удовлетворение потребностей людей (главная задача экономики) напрямую зависело от наличия в природе плодов, ягод, зверей и от успешной их добычи. Добывая блага, люди вступали в определенные отношения между собой. Из предыдущих рассуждений ясно, что производственные отношения на данном этапе могут соответствовать производительным силам (способствовать развитию производительных сил) и обеспечивать непрерывный рост добычи благ или не соответствовать. Возникает вопрос: Какие отношения между первобытными людьми способствовали успешности хозяйствования?

Конечно же, коллективность труда, как один из элементов системы производственных отношений, обеспечивает увеличение добычи благ на данном этапе хозяйствования. На самом 
деле, можно представить себе крайний случай, когда 50 мужчин шли поочередно охотиться на мамонта. Каков результат? Плачевный. А вот если 50 человек вместе шли охотиться на мамонта, то результат может быть вполне успешным. Коллективный труд здесь показывает большую результативность. Или второй случай, когда группа женщин занималась сбором ягод. На одной стороне бурной реки они соберут все ягоды. Чтобы собрать больше ягод, им надо перейти на другую сторону реки. Вброд нельзя, река бурная. Нужно перебросить дерево через реку. Если женщины в одиночку попытаются это сделать, то ничего из этого не получится. А вот если они все вместе возьмутся за дело, то это им удастся. Они перейдут реку и наберут больше ягод. И здесь налицо результативность коллективного труда.

Вопрос: коллективность труда это условие роста производительности труда только при первобытнообщинном способе хозяйствования? А при рабовладельческом способе хозяйствования разве коллективность труда не является условием роста производительности труда (вспомните плантационное хозяйство), а при феодализме, капитализме и т.д.? Мы выявили очень интересное явление: один из элементов производственных отношений первобытнообщинного способа хозяйствования, а именно коллективность труда, не уничтожается при переходе к следующим способам хозяйствования, а сохраняется и входит в системы производственных отношений последующих способов хозяйствования.

Производительность труда при данном способе хозяйствования за счет коллективности труда, конечно же, растет, но не без предела. Можно ли собирательством и охотой удовлетворить более прогрессивные потребности (кроме физиологических)? Да и для удовлетворения этих потребностей нельзя добывать благ больше, чем их имеется в природе (учитывая зависимость этих благ от погодных и иных условий, которые меняются каждый год, можно представить колебания годовых объемов добываемых благ). Границей роста производительности труда за счет только коллективности труда выступает живая природа (флора и фауна). Для дальнейшего роста производительности труда необходимо преодолеть данную ограниченность. Эту задачу решает последующий способ хозяйствования.

2. Экономический прогресс при рабовладельческом способе хозяйствования.

Рабовладельческий способ хозяйствования отличается от первобытнообщинного тем, что, кроме добычи природных благ, в широком масштабе производятся необходимые блага, т.е. используется производство благ. Удовлетворение потребностей людей здесь зависит как от наличия природных благ и их успешной добычи, так и от количества произведенных благ. Производством занимаются рабы. Но рабы не заинтересованы в работе.

Рабы работают только потому, что установлен строгий контроль за мерой трудаа и мерой потребления. Мы выделяем один из элементов системы производственных отношений рабовладельческого способа хозяйствования контроль за мерой труда и мерой потребления. Контроль за трудом рабов осуществляется с целью заставить их работать как можно больше. На самом деле, если раб работает 6 часов, то он производит определенное количество благ, а если он работает 12 часов (15!, 18 часов!?), то произведет значительно больше благ. Рост производительности труда рабов прямо пропорционально зависит от продолжительности рабочего дня. Рабовладелец заставляет раба работать как можно больше.

Контроль за мерой труда и мерой потребления это условие роста производительности труда только в рабовладельческом способе хозяйствования? А в феодальном, капиталистическом и ином способе хозяйствования разве контроль за мерой труда отсутствует, разве не является условием роста производительности труда?. И здесь мы констатируем: один из элементов производственных отношений рассматриваемого способа хозяйствования, а именно контроль за мерой труда и мерой потребления, не уничтожается при переходе к следующим способам хозяйствования, а сохраняется и входит в системы производственных отношений последующих способов хозяйствования!

Производительность труда при рабовладельческом способе хозяйствования, конечно же, растет за счет продолжительности рабочего дня. Наверное, самая большая отдача от раба будет, если он работает 24 часа в сутки (?). Но это невозможно. Границей роста производительности труда за счет рассматриваемого элемента производственных отношений выступают физические (физиологические) возможности.

Последующий способ хозяйствования должен преодолеть эту ограниченность.

3. Экономический прогресс при феодаль- 
ном способе хозяйствования Ограниченность рабовладельческого способа хозяйствования связана с тем, что раб, как не заинтересованный в производстве субъект, работает только по принуждению. Достигнув физиологической границы рабочего дня, данный способ хозяйствования уже не может увеличить производительность труда. Вопрос? Какие отношения между крепостными крестьянами и помещиками могут повысить производительность труда? Новым элементом системы производственных отношений является заинтересованность в результатах труда, связанная с самостоятельностью.

Самостоятельность и заинтересованность стимулируют сознательное повышение производительности труда, без применения насилия со стороны феодала. Не вызывает сомнения то, что данный элемент производственных отношений, возникающий в рамках феодального способа хозяйствования, сохраняется и в последующих способах хозяйствования. Этот элемент стимулирует рост производительности труда. В определенном смысле можно сказать, что феодальный способ хозяйствования обогатил экономическую практику обеспечением самостоятельности и заинтересованности основного и активного субъекта хозяйствования. Для современной российской экономики остается крайне актуальной задачей всестороннее использование резервов самостоятельности и заинтересованности субъектов хозяйствования.

Что касается границы действенности рассматриваемого элемента производственных отношений, то можно отметить следующее. Феодальный способ хозяйствования основан на хозяйствовании большого количества разрозненных мелких производств. Чаще всего, например в России, помещичье хозяйство ограничивалось размерами одной деревни. Конечно же, при таких размерах хозяйства невозможно организовать производство современных машин и оборудования (самолетов, космических аппаратов и др.). Производство чаще всего ограничивалось выращиванием сельскохозяйственной продукции и поделками кустарей.

4. Экономический прогресс при капиталистическом способе хозяйствования

Капиталистический способ хозяйствования призван преодолеть ограниченность феодального способа хозяйствования в повышении производительности труда. Новым элементом, снимающим ограниченность предыдущего спо- соба хозяйствования, является обобществление производства сначала в рамках страны, а потом и всего мира.

Реализация главной задачи экономики разрешение противоречия между безграничными потребностями и ограниченными ресурсами осуществляется в рамках страны. Капитализм разрушил крепостные стены феодалов и расширил рамки производства до границ страны. Появилось национальное хозяйство. Затем появилось и мировое хозяйство, при котором ресурсы разных стран используются для производства благ. Трудно себе представить, чтобы последующие способы хозяйствования могли обойтись без обобществления, без интернационализации хозяйства. Рассматриваемый элемент - обобществление производства это вклад капитализма в экономическую цивилизацию.

Границы роста производительности труда при этом способе хозяйствования. Если рассматривать экономические границы, то их, возможно, и нет. Но зато есть социальные границы. Капитализм, как способ хозяйствования, базируется на безграничной дифференциации по доходу. Эта безграничность и есть ахиллесова пята данного способа хозяйствования. Во всех странах не случайно отслеживается соотношение доходов двух групп населения: десяти процентов (децил) населения с высокими доходами и десяти процентов (децил) населения с низкими доходами. Мировая практика показала если это соотношение не превышает десяти, то общество развивается спокойно, без конфликтов. Качественный труд и предпринимательство в достаточной мере стимулируются. Если же это соотношение значительно превышает эту величину, то в стране начинаются производственные конфликты (забастовки и т.п., вплоть до революций и гражданских войн). Эти конфликты не только не способствуют росту производительности труда, но и уничтожают имеющиеся в стране ограниченные ресурсы (и людей, и здания, и заводы).

Итак, безграничная дифференциация по доходу является границей роста производительности труда при капитализме.

5. Экономический прогресс при коммунистическом способе хозяйствования.

Коммунистический способ хозяйствования в экономическом плане имеет одно принципиальное отличие от предыдущего - он снимает безграничность дифференциации по доходу. 
Уравниловка никогда не входила в теорию коммунистического способа хозяйствования (имея в виду, что в развитом состоянии данный способ хозяйствования не существовал). А вот что касается выравнивания, то оно (опять же, по теории) направлено на то, чтобы дифференциация (а не уравниловка) должна существовать в допустимых пределах, обеспечивающих бесконфликтное, непрерывное развитие производства. Такое состояние в экономике обеспечивается применением общественных фондов потребления.

Специфически коммунистическим элементом производственных отношений является применение общественных фондов потребления (ОФП). С экономической точки зрения принципиальное отличие коммунистического способа хозяйствования от капиталистического - наличие и использование ОФП. За счет общественных фондов потребления повышается уровень доходов населения с низкими доходами и дифференциация по доходам доводится до допустимых пределов, обеспечивающих бесконфликтное развитие производства и непрерывный рост производительности труда. Результативность данного элемента отношений подтверждается практикой его применения во всех странах (в том числе и капиталистических, рыночных). Более того, тем странам, в которых общественные фонды потребления применяются наиболее последовательно, приписываются соответствующие “модели социализма” (шведский и др.).

С экономической точки зрения наиболее "социалистическими” являются в настоящее время страны, идейно открещивающиеся от социализма и являющиеся “витриной капитализма”.

Наличие общественных фондов потребления неотъемлемая часть экономических отношений в любом современном способе хозяйствования. Снятие ограничений дальнейшего роста производительности труда в будущих способах хозяйствования может быть связано с появлением новых отношений (единое интернациональное хозяйство), с широким применением новых ресурсов (информация, наука и др.).

Историческая справка. Имеются данные, что идеологическая надстройка всех способов хозяйствования, начиная с рабовладельческого (Китай, 2000 лет до н.э.), обосновывая прогрессивность очередного способа хозяйствования, непременно утверждала, что это высший и по- следний способ хозяйствования. Такое тупиковое мышление всякий раз не подтверждалось, по-видимому, не подтвердится и в дальнейшем. Поэтому идеологические споры о вечности капитализма или коммунизма смешны.

Возвратимся к нашей гипотезе: Производственные отношения любого способа хозяйствования состоят из двух групп отношений:

- первая группа состоит из элементов, оставшихся от прежних способов хозяйствования;

- вторая группа появляется в рамках но, вой хозяйственной системы.

Рассмотренная гипотеза предполагала, что не все элементы производственных отношений уничтожались, что от предыдущих производственных отношений оставались некоторые элементы. Проведенный анализ производственных отношений в исторической последовательности позволил выявить те элементы производственных отношений, которые сохранялись и переходили в последующие хозяйственные системы. Экономическая цивилизация получила от каждой хозяйственной системы позитивные элементы производственных отношений:

- коллективизм от первобытнообщинного хозяйства;

- контроль за мерой труда и потребления от рабства;

- самостоятельность и заинтересованность от феодализма;

- обобществление производства от капитализма;

- социальную защищенность через общественные фонды потребления от коммунизма.

Мы выявили только по одному элементу от каждой хозяйственной системы, хотя на самом деле их сохранилось значительное количество. Но и этого достаточно для вывода о том, что производственные отношения предыдущего способа хозяйствования уничтожались не полностью. Уничтожались только негативные элементы, а позитивные сохранялись.

Полученного вывода достаточно для того, чтобы утверждать, что противоречия между производственными отношениями и производительными силами не достигали антагонизма и нет основания для уничтожения всей системы производственных отношений. Таким образом, гипотеза оказывается доказанной и превращается в новую теорию (концепцию) экономического прогресса. 
Новая концепция является эволюционной теорией экономического прогресса, и она вполне может заменить революционную концепцию экономического прогресса. Эта теория более адекватно отражает экономическую действительность. Обратимся к экономической практике, которая дает немало примеров развития общества, и в первую очередь экономики, эволюционно и поэтому эффективно.

Кто вспомнит, сколько революций пережила, например, Швеция? Мы не помним. Странно, революций не было, а экономика страны развивалась и развивается прогрессивно? Можно было бы привести примеры и по другим странам. Но и этого достаточно для иллюстрации прогрессивного развития экономики без революций и других потрясений. Таким образом, и экономическая теория, и экономическая практика подтверждают возможность эволюционного развития.

Не следует бросаться из одной крайности (революционной) в другую крайность (эволюционную), т.е. утверждать либо одну теорию, либо другую. Речь идет именно о возможности и желательности эволюционного развития. Другие, неэкономические, причины могут обусловить революционное развитие, но это уже будет вопреки экономической закономерности и целесообразности.

Задача современной экономики - использовать все позитивные элементы экономических отношений независимо от их происхождения (принадлежности к способу производства), уничтожая негативные экономические отношения.

Таким образом, и экономическая теория, и экономическая практика подтверждают возможность эволюционного развития.

Задача современной экономики - использовать все позитивные элементы экономических отношений независимо от их происхождения (принадлежности к способу производства), уничтожая негативные экономические отноше- ния.

Итак, на страноведческом уровне современный экономический прогресс обеспечивается снятием безграничности дифференциации по доходу. А можно на минуту отвлечься от экономики и вспомнить авторов этого позитивного элемента экономических отношений? Неужели Советский Союз!! И все страны используют это предложение?? Way! Wonderful!!

А теперь попытаемся спроектировать наши исследования для мировой экономики в целом.

Сегодня мировая экономика примерно одного типа - № 5 . Во всех странах есть экономики, в которых в большей или меньшей мере присутствуют позитивные элементы экономических отношений всех экономических формаций. Это никого не удивляет. Главный коммунист рукопожатен главному капиталисту. Надстройка уже не диктует базису. А экономического мира сегодня нет. В чем же дело?

Можно предположить, что дело не в базисе, а в бизнесе. На первый план выходит децильный коэффициент 144 стран мира. Если сравнить 10 процентов богатых стран с 10 процентами бедных стран, то получим соотношение, далекое от оптимального. На глобальном уровне экономический прогресс может быть обеспечен достижением оптимального соотношения подушевого богатства стран. Это уже задача $\mathrm{OOH}$, других международных организаций и политиков всех стран. Таким образом, может оправдаться и эволюционная концепция глобального экономического прогресса.

\section{Без цветных революций.}

Децильный коэффициент может быть один из вопросов обсуждения руководителей 5 ведущих стран мира - учредителей $О О \mathrm{H}$.

Общественный фонды потребления, апробированные впервые в СССР и используемые во многих странах, разумно применить во всех странах мира в интересах всего населения планеты.

\section{Библиографический список}

1. Глазьев С.Ю. Теория долгосрочного технико-экономического развития. М., 1993.

2. Дубровский C.M. К вопросу о сущности «азиатского» способа производства, феодализма, крепостничества и торгового капитала // Историк-марксист. 1930. Т. 16.

3. Карл Маркс. Капитал. Том первый. Послесловие ко второму изданию. К. Маркс, Ф. Энгельс, Собр. соч., изд. 2, т. 23.

4. Малышев П.А., Стерликов Ф.Ф.. Законы экономической жизни. М.; Мысль, 1991. 
5. Семенов Ю.И. Категория «общественно-экономический уклад» и ее значение для философской и исторической наук // Философские науки. 1964. № 3.

6. Стерликов Ф.Ф., Гуськова М.Ф., Стерликов П.Ф.Диалектика экономического прогресса. Экономические науки, 2006, № 7, с. 115-123.

7. Сычев Н.В. Многоукладная экономика (политико-экономическое исследование). М., 1999.

8. Сычев Н.В. Структура экономического уклада (дискуссионные аспекты). Вестник Института экономики Российской академии наук 3/2014

9. Теория общественно-экономической формации. М., 1982

10. Черняк В.К. Структура экономического развития. Киев, 1981.

11. Яковец Ю.В. История цивилизаций. М., 1995. 